\title{
Capacidade Relacional e Alianças Estratégicas de Pesquisa e Desenvolvimento
}

\author{
Relationship Capability and Strategic Alliances for Research and Development
}

\author{
Taísa Scariot Preusler ${ }^{10}$ \\ Priscila Rezende da Costa ${ }^{2}$ \\ Tatiane Baseggio Crespi ${ }^{1}$ \\ Geciane Silveira Porto ${ }^{3}$
}

\section{RESUMO}

Contexto: a Empresa Brasileira de Pesquisa Agropecuária tem exercido importante papel em pesquisa e desenvolvimento para a geração de inovações. Grande parte dessas inovações é devida às alianças de pesquisa e desenvolvimento com parceiros externos, estimulando potencialmente a capacidade relacional, isto é, um construto de gestão estratégica de alianças, com proposições processuais ainda não verificadas empiricamente. Objetivo: o objetivo geral deste estudo foi explorar como os processos da capacidade relacional podem contribuir para a geração de inovações. Métodos: realizou-se uma pesquisa qualitativa, utilizando o método de estudo de caso, a partir de entrevistas, análise documental e observação. Três alianças estratégicas de pesquisa e desenvolvimento, envolvendo a Empresa Brasileira de Pesquisa Agropecuária e parceiros externos, constituíram o corpus de análise. Resultados: a principal contribuição para o avanço do conhecimento foi um modelo interorganizacional para geração de inovações, a partir de alianças estratégicas de pesquisa e desenvolvimento, fundamentado nas evidências empíricas dos processos da capacidade relacional da Empresa Brasileira de Pesquisa Agropecuária e dos seus parceiros externos. Conclusão: esse novo modelo fornece mais clareza sobre como uma empresa pública de pesquisa absorve conhecimento e evidencia, de forma inédita, os processos de institucionalização e de transbordamento da capacidade relacional.

Palavras-chave: inovação agropecuária; alianças estratégicas de pesquisa e desenvolvimento; capacidade relacional.

Classificação JEL: L1, L2, O32.

' Universidade Nove de Julho, São Paulo, SP, Brasil.

${ }^{2}$ Universidade Nove de Julho, Programa de Pós-Graduação em Administração, São Paulo, SP, Brasil.

${ }^{3}$ Universidade de São Paulo, Faculdade de Economia, Administração e Contabilidade de Ribeirão Preto, Ribeirão Preto, SP, Brasil.

\section{ABSTRACT}

Context: the Brazilian Agricultural Research Organization has played an important role in research and development to generate innovations. Many of these innovations are generated through research and development alliances with external partners. This stimulates the potential for relationship capability, i.e., a strategic management construct of alliances with procedural proposals that have not yet been verified empirically. Objective: the general aim of the study was to explore how relationship capability processes can help to generate innovations. Methods: qualitative research was conducted using the case study method, based on interviews, document analysis and observation. Three strategic research and development alliances involving the Brazilian Agricultural Research Organization and external partners constituted the analysis corpus. Results: the principal contribution to the advance of knowledge was an interorganizational model for generating innovations based on strategic research and development alliances, founded on the empirical evidence of the relationship capability processes of the Brazilian Agricultural Research Organization and its external partners. Conclusion: this new model provides greater clarity regarding how a public research company absorbs knowledge and unprecedented evidence of the processes of institutionalization and the overflow of relationship capability.

Keywords: agricultural innovation; strategic alliances for research and development; relational capability.

Cite as: Preusler, T. S., Costa, P. R. da, Crespi, T. B., \& Porto, G. S. (2020). Relationship capability and strategic alliances for research and development. Revista de Administração Contemporânea, 24(3), 201-217. https://doi.org/10.1590/1982-7849rac202018018

Editor-chefe: Wesley Mendes-Da-Silva (Fundação Getulio Vargas, EAESP, Brasil) Pareceristas: Dimária Silva e Meirelles (Universidade Presbiteriana Mackenzie, Brasil) Paulo Cruvinel (Empresa Brasileira de Pesquisa Agropecuária - Embrapa, Brasil) (6)

\# de revisores convidados até a decisão:

\begin{tabular}{|c|c|c|c|c|c|c|c|c|c|}
\hline & 1 & 2 & 3 & 4 & 5 & 6 & 7 & 8 & 9 \\
\hline $1^{a}$ rodada & 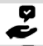 & 9 & & & & & & & \\
\hline $2^{a}$ rodada & 2 & (x) & & & & & & & \\
\hline $3^{a}$ rodada & $\stackrel{9}{2}$ & & & & & & & & \\
\hline $4^{a}$ rodada & 2 & & & & & & & & \\
\hline
\end{tabular}




\section{INTRODUÇÃO}

A agropecuária é um dos setores mais relevantes para a economia brasileira, cuja cadeia produtiva completa é responsável por aproximadamente $22,5 \%$ do Produto Interno Bruto (PIB) e também pelos números do comércio exterior, já que um em cada quatro produtos da agropecuária no mundo é de origem brasileira (Empresa Brasileira de Pesquisa Agropecuária [EMBRAPA], 2017). Nesse sentido, a Empresa Brasileira de Pesquisa Agropecuária (EMBRAPA) tem exercido um importante papel em P\&D para a geração de inovações, elevando o índice de produtividade na agricultura, o que contribui para a garantia da segurança alimentar (Nehring, 2016) e o desenvolvimento de um sistema agrícola mais sustentável (Food and Agriculture Organization [FAO], 2016). Muitas dessas inovações são desenvolvidas a partir de alianças estratégicas, celebradas entre a EMBRAPA e parceiros externos, incluindo empresas, institutos e fundações de pesquisa, cooperativas e universidades, os quais, a partir dessa interação, conseguem resolver conjuntamente os desafios relacionados à agropecuária (Schut et. al., 2016).

As alianças estratégicas têm sido consideradas uma alternativa estrutural à inovação, haja vista a possibilidade de complementação de recursos, acesso a novos mercados e redução de custos (Almeida \& Costa, 2017; Dyer \& Singh, 1998). Entretanto, a sua formação não é um processo simples e o índice de insucesso tem sido muito alto. As chances de um desempenho satisfatório de uma aliança aumentam se as instituições envolvidas desenvolverem a capacidade de trocar continuamente informações e conhecimentos com os parceiros (Shakeri \& Radfar, 2017; Patterson \& Ambrosini, 2015), estabelecer uma estrutura de governança para a gestão das alianças (Heimeriks \& Duysters, 2007; Milagres, Rezende, \& Silva, 2017), selecionar os parceiros adequados, gerenciando conflitos e estabelecendo confiança mútua (Shakeri \& Radfar, 2017), bem como criar mecanismos de proteção de ativos (Sorrentino \& Garraffo, 2012; Costa \& Porto, 2014), de forma a trazer vantagens a todas as partes envolvidas (Wang \& Rajagopalan, 2015).

Esses processos de gestão estratégica das alianças integram o construto da capacidade relacional (CR) (Schilke \& Goerzen, 2010), cujos resultados potenciais são as chamadas rendas relacionais, ou seja, benefícios em termos de ganhos econômicos, resultados científicos e tecnológicos, que somente são obtidos por meio de uma relação interorganizacional (Zhang, Li, \& Li, 2017). Apesar da relevância da CR, nota-se que proposições processuais ainda não foram verificadas empiricamente, a saber:

(A) A CR pode se manifestar de forma distinta em empresas públicas de pesquisa que estabelecem alianças de P\&D com parceiros externos, incluindo os conectados (quando a inovação é estimulada no parceiro, predominantemente, pela demanda do mercado) (Lhuillery \& Pfister, 2009) e não conectados ao mercado (quando a inovação é impulsionada no parceiro predominantemente pela pesquisa) (Appio, Martini, Petruzzelli, Neirotti, \& Van Looy, 2017);

(B) Em uma empresa pública de pesquisa, há possibilidade de sistematização de processos de gestão estratégica de alianças (Crossan, Lane, \& White, 1999), oportunizando a adaptação ou replicação desses processos em alianças futuras; sendo assim, pode-se considerar a CR amadurecida, ou seja, institucionalizada (Lorenzoni \& Lipparini, 1999);

(C) Nas alianças estratégicas de P\&D de uma empresa pública de pesquisa, há possibilidade de transbordamentos de processos relacionais entre os parceiros, culminando em aprimoramentos internos, ou, ainda, na adoção de novas práticas de P\&D (Lin \& Darnall, 2015; Walsh, Lee, \& Nagaoka, 2016).

Dada a necessidade de verificar essas proposições a partir de evidências empíricas processuais, considerando o importante papel que a inovação agropecuária desempenha no país, e tendo em vista que a formação de alianças estratégicas de P\&D tem sido cada vez mais utilizada como forma de geração de inovações, buscou-se, neste estudo, explorar como os processos da CR podem contribuir para a geração de inovações (Walsh et al. 2016).

Diante desse objetivo, a CR é aqui investigada a partir da perspectiva da capacidade dinâmica (Schilke \& Cook, 2015; Niesten \& Jolink, 2015) de uma empresa que, por meio de processos organizacionais, busca criar, expandir ou transformar a base de recursos (Helfat et al., 2009), possibilitando às empresas lidarem com a mudança de ambientes (Donada, Nogatchewsky, \& Pezet, 2016).

Especificamente, adotou-se o modelo de Schilke e Goerzen (2010) para a operacionalização da pesquisa, por ser atual e também difundido internacionalmente (283 citações), sendo as categorias de análise: coordenação interorganizacional, transformação da aliança, aprendizagem, proatividade em alianças e portfólio de alianças. Esta última não foi utilizada, visto o foco estar nas alianças díades, não no portfólio.

Destaca-se, ainda, que este estudo considerou os seguintes antecedentes da CR: a experiência no estabelecimento de alianças e a estrutura de governança das alianças (Schilke \& Goerzen, 2010). A experiência prévia, acumulada pela formação de alianças estratégicas anteriores, possibilita às organizações o desenvolvimento da habilidade de escolher parceiros em potencial, a fim de complementar os recursos, gerenciar (Heimeriks \& Duysters, 2007; Almeida \& Costa, 2017) e realizar ajustes, quando necessários (Heimeriks \& Duysters, 2007). Empresas que detêm uma estrutura voltada à administração das alianças conseguem centralizar as informações, facilitar a comunicação entre os setores (Hoang \& Rothaermel, 2005), desenvolvendo 
meios para gerir as alianças de forma mais eficiente (Heimeriks \& Duysters, 2007). Sobre a estrutura de governança da aliança, destaca-se sua formalização, ou seja, os diferentes níveis relacionados à proteção de ativos (Sorrentino \& Garraffo, 2012; Costa \& Porto, 2014), considerando os parceiros e objetos das alianças.

Em relação à contribuição para o avanço do conhecimento, destaca-se que o estudo oportunizou a proposição de um modelo interorganizacional para geração de inovações a partir de alianças estratégicas de P\&D, fundamentado nas evidências empíricas dos processos da capacidade relacional da EMBRAPA e dos seus parceiros externos. Esse novo modelo fornece mais clareza sobre como uma empresa pública de pesquisa absorve conhecimento e evidencia, de forma inédita, os processos de institucionalização e de transbordamento da CR.

\section{REFERENCIAL TEÓRICO}

Schilke e Goerzen (2010) definiram que a CR é dimensionada a partir da coordenação e da aprendizagem interorganizacional, proatividade e transformação da aliança. A coordenação interorganizacional é composta por um conjunto de processos específicos, os quais são construídos de forma consensual entre parceiros para a execução de tarefas e investimentos dos recursos da aliança (Gulati, Lawrence, \& Puranam, 2005). Essa coordenação desempenha um papel importante, facilitando a interação de forma a garantir que as alianças individuais sejam governadas de maneira eficiente, principalmente as que possuem parceiros de natureza distinta, com dissimilaridades relacionadas aos objetivos e expectativas (como indústrias e universidades), amenizando e solucionando conflitos interpretativos (Estrada, Faems, Cruz, \& Santana, 2016).

A aprendizagem organizacional está relacionada a processos e mecanismos para facilitar a articulação, codificação, compartilhamento e internalização do know-how dos parceiros das alianças e a transferência de conhecimento nos limites da empresa (Shakeri \& Radfar, 2017). Conhecida ainda como capacidade absortiva, a capacidade dinâmica permite à empresa criar novos recursos internos por meio da busca, aquisição, assimilação, transformação e exploração do conhecimento externo, desenvolvendo um processo de inovação (Patterson \& Ambrosini, 2015).

Cabe salientar que, pela rotina de detecção, a proatividade favorece as organizações a identificarem oportunidades e parceiros em potencial, com fins de aquisição de recursos externos (Schilke \& Goerzen, 2010). As empresas proativas conseguem responder e agir de forma preventiva em relação às novas oportunidades (Schilke \& Goerzen, 2010). Isso se dá porque a transformação da aliança está relacionada à flexibilidade que os parceiros possuem para reagir às condições que venham a ser alteradas ao longo da aliança - fenômeno natural e desejável, uma vez que não se pode esperar um modelo perfeito desde o início (Reuer \& Zollo, 2000). Sendo assim, alterações nos contratos, nos mecanismos de governança e de pessoal são recorrentes em aproximadamente $40 \%$ das alianças estratégicas. Dessa forma, se após a formação das alianças, instituições parceiras desenvolvem processos que as modificam, conseguindo alavancar recursos complementares e aprender umas com as outras diante dos desafios, colocados por conflitos, gastos inesperados e riscos morais, elas conseguem alavancar valor (Wang \& Rajagopalan, 2015), contribuindo para uma colaboração eficiente (Reuer \& Zollo, 2000).

Portanto, quando empresas possuem estruturas organizacionais estabelecidas e pessoas especializadas, os processos de gestão estratégica das alianças de P\&D podem ser institucionalizados (Crossan et al., 1999), criando, assim, a expectativa de que se tenha alcançado uma CR amadurecida. Nesse sentido, destaca-se a proposição P1: à medida que as empresas institucionalizam os processos de coordenação interorganizacional, de proatividade em aliança, de aprendizagem organizacional e de transformação das alianças, mais madura será sua capacidade relacional.

Institutos de pesquisa (não conectados ao mercado) são considerados importantes parceiros de P\&D, já que eles realizam pesquisas para desenvolvimento de novos conhecimentos e tecnologias em áreas específicas, contribuindo para a promoção de inovações (Etzkowitz, 2017). Por outro lado, cabe às instituições interligadas com a prática a responsabilidade de colocar essas inovações no mercado (Lundvall, 1988). A partir dessa lógica, tem-se a expectativa de que em alianças de P\&D ocorra o transbordamento interorganizacional de processos entre as empresas e seus parceiros, ou seja, esses atores institucionalizam e, posteriormente, transferem processos inerentes às atividades de $\mathrm{P} \& \mathrm{D}$, resultando em aprimoramento ou novas práticas de absorção de conhecimento. Assim, delineiam-se as proposições P2: em alianças estratégicas de $\mathrm{P} \& \mathrm{D}$, processos inerentes à pesquisa são transbordados da empresa pública de pesquisa para os parceiros (conectados ou não conectados); e P3: em alianças estratégicas de $\mathrm{P} \& \mathrm{D}$, processos inerentes ao desenvolvimento são transbordados dos parceiros (conectados ou não conectados ao mercado) para a empresa pública de pesquisa.

\section{METODOLOGIA}

Para atingir o objetivo geral deste estudo, realizou-se uma pesquisa de natureza qualitativa, sendo que o ambiente do fenômeno estudado foi utilizado como fonte de dados, e o pesquisador, como um instrumento fundamental para a coleta 
desses dados, bem como para a seleção, verificação e interpretação das informações (Creswell, 2017). A abordagem foi a exploratória, por meio de um processo de interação entre o pesquisador, os participantes e os locais estudados, a fim de modificar ou clarificar conceitos (Creswell, 2017). Como método, utilizouse o estudo de caso, uma vez que não havia domínio sobre o fenômeno estudado, permitindo, assim, verificar, ligar e comparar as informações obtidas (conhecimento prático) com as proposições do estudo (conhecimento teórico) (Godoy, 1995).

Para a investigação do problema, a unidade de análise selecionada foi a EMBRAPA, por atender aos seguintes critérios: (a) é reconhecida como um dos principais atores da pesquisa agropecuária brasileira; (b) possui experiência na formação de alianças para o desenvolvimento de inovações agropecuárias; e (c) possui evidências de $C R$, pois promove integração e interações entre os diferentes atores do Sistema Nacional de Pesquisa Agropecuária (SNPA), incluindo organizações com fins lucrativos (empresas, cooperativas, institutos de pesquisa privados) e sem esses fins (universidades públicas, institutos de pesquisa públicos e organizações sociais).

Considerando o caso EMBRAPA, foram selecionadas três alianças para análise, a partir dos seguintes fundamentos: alianças estratégicas de P\&D que geraram inovações de relevância social, econômica ou ambiental; e, alianças estratégicas que tenham sido celebradas nos últimos 15 anos. A escolha do período se refere ao fato de que, como a EMBRAPA tem em seu histórico o desenvolvimento de cultivares e, para obter uma nova cultivar, leva-se, em média 12 anos, optou-se por utilizar esse período para que alianças de $\mathrm{P} \& \mathrm{D}$, com foco em pesquisa de longo prazo, pudessem ser incluídas na pesquisa.

Realizou-se consulta, no site da EMBRAPA, na categoria de produtos, processos e serviços (https:// www.embrapa.br/produtos-processos-e-servicos; recuperado em 10 de Janeiro, 2017), sobre as soluções tecnológicas desenvolvidas pela empresa. Ao aplicar o filtro para o período compreendido entre 2002 a 2017, o site apresenta um total de 1.794 tecnologias. Esse resultado abrange tecnologias que foram geradas pela EMBRAPA e também entre a empresa e parceiros externos. Posteriormente, houve consulta acerca das cultivares registradas em nome da empresa, no Registro Nacional de Cultivares (RNC), pelo site http://www.agricultura.gov.br/guiade-servicos/registro-nacional-de-cultivares-rnc; recuperado em 10 de Janeiro, 2017. Em janeiro de 2017, a EMBRAPA possuía aproximadamente 1.580 cultivares registradas. E, por fim, buscou-se, no site do Instituto Nacional da Propriedade Industrial (http://www.inpi.gov.br/; recuperado em 15 de Janeiro, 2017), as patentes já registradas ou com pedido de registro pela EMBRAPA.
Considerando as alianças estratégicas formadas pela EMBRAPA com parceiros externos para o desenvolvimento de tecnologias, a partir dos critérios supracitados, três alianças de P\&D foram selecionadas de forma intencional para a realização do estudo, que são: (a) embalagens anatômicas para frutas, desenvolvidas entre a unidade da EMBRAPA Agroindústria de Alimentos e institutos de pesquisa públicos (IMA e INT) - inovação com benefícios ambientais, econômicos e sociais, que resultou em 39 patentes; (b) cultivar de cevada BRS Quaranta, desenvolvida entre a unidade da EMBRAPA Trigo, Fundação de Pesquisa (FAPA) e empresa (AmBev) inovação que traz benefício econômico e social, ressaltando que $90 \%$ das cultivares de cevada cervejeira no mercado são desenvolvidas pela EMBRAPA; e (c) INOVA-Bti - inseticida biológico, desenvolvido entre a Unidade da EMBRAPA Recursos Genéticos e Biotecnologia, um instituto de pesquisa privado (IMAmt) e uma cooperativa (COMDEAGRO). Tal inovação é geradora de grande benefício social, uma vez que permite a redução da proliferação do mosquito Aedes aegypti, transmissor dos vírus da Dengue, Chikungunya e Zika.

Em relação à coleta de dados, foram realizadas 10 entrevistas: 3 com os chefes de T\&T das unidades selecionadas; 1 com o chefe-geral da unidade de Recursos Genéticos e Biotecnologia (CENARGEN); e 6 com pesquisadores que tiveram a participação direta tanto nas atividades de P\&D como na coordenação das alianças selecionadas, sendo 3 da EMBRAPA e 3 das instituições parceiras que atuaram diretamente nas alianças para desenvolvimento das tecnologias nas unidades. Com exceção da entrevista com o pesquisador da FAPA, realizada via Skype, todas as outras aconteceram presencialmente. Entrevistouse, ainda, a Coordenadora de Apoio à Inovação e Propriedade Intelectual da EMBRAPA, por telefone, a fim de identificar as características relacionadas à formação de alianças da empresa e a evolução da formalização. Buscou-se, ainda, entender as questões de propriedade intelectual e o tempo de duração das alianças com diferentes objetivos. Para a realização das entrevistas, foi utilizado um roteiro semiestruturado, segundo o modelo de Schilke e Goerzen (2010), e todas as entrevistas foram gravadas, totalizando 6 horas e 48 minutos de gravação.

Zamberlan et al. (2014) sugerem que o mais adequado é buscar outras fontes para ratificar os dados coletados pela entrevista. A observação, nesse sentido, também foi utilizada por este estudo, pois possibilita ao pesquisador identificar e obter informações, registradas em diário de campo, decorrentes do ambiente, de expressões, comportamentos, fatos e sentidos dos indivíduos, coletados no momento das entrevistas in loco (Zamberlan et al., 2014; Godoy, 1995). 
Além disso, foram obtidos dados secundários nos sites da EMBRAPA e dos seus parceiros; consulta de cultivares registradas em nome da EMBRAPA, no RNC; levantamento e confirmação de informações de patentes, em pesquisa no site do Instituto Nacional da Propriedade Industrial (http://www.inpi.gov. br/; recuperado em 15 de Janeiro, 2017); e análise de documentos, como contratos, projetos e folders, arquivos, relatórios, atas de reuniões, regulamentos, jornais e revistas.

Com tais fontes de dados, definiu-se as categorias de análise do estudo: (1) institucionalização da CR; e (2) transbordamento de processos inerentes à pesquisa e ao desenvolvimento, a partir de dados primários (entrevistas semiestruturadas e observação não participante) e secundários (documentos) (Tabela $1)$.
Para operacionalizar cada categoria de análise, utilizou-se o procedimento denominado triangulação (Zamberlan et al., 2014), isto é, evidências de diferentes fontes foram coletadas e utilizadas para responder às perguntas norteadoras da pesquisa, a fim de se obter conclusões mais consistentes. A análise agregada de cada categoria e suas evidências, obtidas de diferentes fontes, possibilitou, então, a interpretação das proposições, elaboradas a partir da fundamentação teórica (Tabela 1).

Vale detalhar que os dados primários e secundários coletados foram submetidos à análise de conteúdo (Creswell, 2017), envolvendo a organização e classificação a partir de categorias sistematizadas, o que, por sua vez, auxiliou na redução e triangulação dos dados, garantindo a validade e a robustez das análises (Tabela 1). Além disso, a síntese da matriz de amarração pode ser verificada na Tabela 1 .

Tabela 1. Matriz metodológica de amarração.

Natureza
Abordagem
Método
Contexto da pesquisa
Unidade de análise
Perguntas norteadoras da categoria de análise
De forma geral, a iniciativa da formação da parceria para
realização de P\&D parte da sua instituição ou do parceiro? A
instituição possui um departamento formal, manuais, normas,
guia etc.? Existe diferenciação na formalização de parcerias para
pesquisa e parcerias para desenvolvimento? A Instituição adota
mecanismos para evitar o comportamento oportunista, roubo de
informações e conhecimentos unilaterais? O nível de formalização
das parcerias são padronizados ou existem diferenças de acordo
o objeto da aliança ou natureza do parceiro? Como cada parceria
de P\&D é coordenada? Como as atividades são sincronizadas?
É comum haver requisições de mudanças "procedimentais" ou
"contratuais" nas parcerias? É comum o surgimento de conflitos
de interesses nas parcerias?

Qual é a percepção da instituição em relação à formação de parcerias para a realização de P\&D? Quais conhecimentos, recursos ou ativos foram buscados para essa parceria? Sua instituição consegue aprender com os parceiros? Há também processos de transferência desse conhecimento? Quais atividades foram desenvolvidas por cada parceiro? Qual a principal expertise do parceiro? Quais os principais impactos que essa inovação gerou?
Qualitativa (Creswell, 2017).

Exploratória (Creswell, 2017).

Estudo de caso (Godoy, 1995).

EMBRAPA

Três alianças estratégicas de P\&D entre a EMBRAPA e parceiros externos

\section{Categorias de análise e Procedimentos de Procedimentos de} proposições coleta de dados análise de dados

Nota. Fonte: Elaborada pelos autores, a partir de dados da pesquisa.

\section{RESULTADOS}

Considerando as características das alianças investigadas, bem como a descrição dos parceiros envolvidos e das inovações geradas, apresenta-se a seguir uma síntese dos casos (Tabela 2).

Análise de conteúdo e triangulação

\author{
Entrevista, anális \\ documental \\ projetos) \\ observação não \\ de campo).
}
Análise de conteúdo e triangulação participante (diário de campo).
ntrevista, análise documental (contratos (contratos

\section{(n)}


Tabela 2. Síntese intracaso das alianças estratégicas de P\&D investigadas.

\begin{tabular}{lccc}
\hline Características & \multicolumn{2}{c}{ Descrição sintetizada } \\
\cline { 2 - 4 } Tipo de inovação & $\begin{array}{c}\text { Aliança (1) } \\
\text { Embalagens anatômicas para frutas }\end{array}$ & $\begin{array}{c}\text { Aliança (2) } \\
\text { Cultivar de cevada - BRS Quaranta } \\
\text { Processo agroindustrial }\end{array}$ & $\begin{array}{c}\text { INOVA-Bti - inseticida (3) biológico } \\
\text { INovação) }\end{array}$ \\
\hline Tema associado & $\begin{array}{c}\text { Agroindústria, segurança alimentar, } \\
\text { nutrição e saúde. }\end{array}$ & $\begin{array}{c}\text { Agricultura familiar, agroindústria, } \\
\text { melhoramento genético e produção } \\
\text { vegetal. }\end{array}$ & Bioprodutos, formulações e congêneres. \\
\hline Ano de lançamento & 2011 & 2002 & 2016 \\
\hline Ano de conclusão & 2015 & 2015 & 2016 \\
\hline $\begin{array}{l}\text { Principais } \\
\text { aplicações }\end{array}$ & Transporte e armazenamento de frutas & $\begin{array}{c}\text { Reservatórios de água para o consumo, } \\
\text { locais apropriados para a proliferação } \\
\text { ou ligado a outros meios de controle do } \\
\text { mosquito. }\end{array}$ \\
\hline $\begin{array}{l}\text { Principais } \\
\text { impactos }\end{array}$ & $\begin{array}{c}\text { Diminuição de perdas e desperdícios das } \\
\text { frutas; aumento da eficiência no trabalho; } \\
\text { decomposição mais rápida na natureza. }\end{array}$ & $\begin{array}{c}\text { Aumento de produtividade; dispensa } \\
\text { parcial ou total das aplicações de } \\
\text { fungicida. }\end{array}$ & $\begin{array}{c}\text { Controle das larvas do mosquito Aedes } \\
\text { aegyti, transmissor do vírus da Dengue, } \\
\text { Chikungunya e Zika; não prejudica o meio } \\
\text { ambiente. }\end{array}$ \\
\hline
\end{tabular}

Depósitos de patentes

Publicações

39
Não se aplica (segredo industrial).
1 folder

4 artigos e 2 capítulos de livro

Pesquisa: levantamento dos problemas encontrados pelos produtores para transporte e armazenamento de frutas e hortaliças; seleção da fibra mais

Atividades de P\&D adequada para formação do compósito.

Desenvolvimento: agregar fibra no

compósito, modelagem e design das embalagens.

\begin{tabular}{lc}
\hline $\begin{array}{l}\text { Principais } \\
\text { parceiros }\end{array}$ & IMA (não conectado ao mercado) e INT \\
(não conectado ao mercado).
\end{tabular}

parceiros (não conectado ao mercado).

2010

5 anos (médio prazo)

Duração da aliança

Termo de convênio

Desenvolvimento: melhoramento genético da cevada.

Pesquisa: experimentação para avaliação do desempenho agronômico das linhagens.

\section{6}

Indicacão de estirpes; otimizacão do processo de producão das estirpes: desenvolvimento de formulações de alta qualidade e avaliação da toxidade dos produtos.
IMAmt (não conectado) e COMDEAGRO (conectado ao mercado).

\begin{tabular}{lcc}
\hline $\begin{array}{l}\text { Instrumento de } \\
\text { formalização }\end{array}$ & Termo de convênio & $\begin{array}{c}\text { Contrato de cooperação técnica e } \\
\text { financeira }\end{array}$ \\
\hline
\end{tabular}

Objetivo da aliança

Desenvolvimento de embalagens valorizáveis para o acondicionamento de frutas e hortaliças.
Estabelecimento de condições para cooperação técnica e financeira entre a EMBRAPA, a AmBev e a FAPA, para a obtenção de novas cultivares de cevada.

Composição do $\mathrm{R} \$ 4.179 .000,00$ (aporte) recurso financeiro
$\mathrm{R} \$ 4.199 .195,30$, sendo que $\mathrm{R} \$$
568.972,30 se refere à participação R\$ 1.267.611,00, da FAPA. EMBRAPA; R\$ 1.362.612,00, da AmBev; e

1 ano (curto prazo)

Contrato de cooperação técnica

Desenvolvimento de produtos à base de Bacillus thuringiensis var. israelenses e de Bacillus sphaericus, para controle de Simulium spp, Culex quinquefasciatua, Anopheles spp e Aedes aegypti.

Sem repasse de recursos financeiros entre as instituições. Valores aportados: EMBRAPA

$\mathrm{R} \$ 120.000,00 ;$ IMAmt

R \$ 60.000,00; COMDEAGRO $\mathrm{R} \$ 60.000,00$.

Obter as autorizações necessárias para cumprimento da legislação de acesso ao patrimônio genético; responsabilizar-se pelas atividades do Plano de Trabalho;

e disponibilizar as estirpes a serem utilizadas no contrato.
Atividades de cruzamentos; avanço
de gerações e seleção de progênies e realização de testes de avaliação e de valor de cultivo e uso - VCU.
Parceiro IMAmt: disponibilizar recursos humanos para a execucãa do contrato, responsabilizando-se pelo pagamento

das despesas; realizar contratação

de pesquisador; realizar compras

Parceiro AmBev: realização de testes de Parceiro IMA: selecionar, tratar e
caracterizar rejeitos agrícolas que

Papel do pudessem ser utilizados nos compósitos

polímeros; selecionar os materiais poliméricos mais adequados à preparação dos compósitos.

e validação de desempenho agronômico

de cultivares registradas em nome da EMBRAPA.

(materiais de consumo e equipamentos) e contratações de serviços.

Parceiro COMDEAGRO: obter as

Parceiro FAPA: realização de testes de

Parceiro INT: desenvolvimento dos
projetos das embalagens primárias,

Papel do parceiro 2 secundárias e terciárias, no campo do design. avaliaç̃o de qualidade de malte e cerveja; validação de desempenho agronômico de cultivares registradas em nome da EMBRAPA; testes de avaliação e de VCU em linhagens desenvolvidas pela EMBRAPA. utorizações necessárias para regular cumprimento da legislação de acesso ao patrimônio genético; responsabilizar-se patrimonio gestão do processo de obtenção dos pela gestão do processo de obtenção dos
registros dos produtos que viessem a ser registros dos produtos que viessem a ser
obtidos, junto às autoridades competentes e produzir o bioinseticida.

Nota. Fonte: Elaborada pelos autores, com base nos dados da pesquisa. 
Alianças estratégicas referem-se a ligações entre instituições (Kale, Dyer, \& Singh, 2002), que se unem para ter acesso ou desenvolvimento de recursos, conhecimento, know-how etc. (Ortiz-de-Urbina-Criado, Montoro-Sánchez, \& Mora-Valentín, 2014; Bleeke \& Ernst, 1991; Powell, 1987), para alcançar distintos objetivos, entre os quais o desenvolvimento conjunto de atividades de P\&D, por meio de contratos bilaterais (Powell, Koput, \& Smith-Doerr, 1996; Klotzle, 2002).

As embalagens estudadas foram desenvolvidas por meio de aliança estratégica para P\&D (Aliança 1, descrita na Tabela 2), enquadrando-se, pois, na teoria da Visão Baseada em Recurso (VBR), já que sua celebração se deu como forma de ter acesso a recursos idiossincráticos dos parceiros (Barney, 1991). As instituições que participaram dessa aliança formalmente foram: EMBRAPA Agroindústria de Alimentos; Instituto Nacional de Tecnologia (INT); Instituto de Macromoléculas (IMA) da Universidade Federal do Rio de Janeiro (UFRJ); e a Fundação Coordenação de Projetos, Pesquisas e Estudos Tecnológicos (COPPETEC). O Banco Nacional de Desenvolvimento Econômico e Social (BNDES) foi o órgão de fomento e houve, ainda, a participação informal da Associação dos Produtores de Frutas do Rio de Janeiro.

Dentre as atividades de pesquisa realizadas na Aliança 1 (embalagens anatômicas para frutas), estava o levantamento de problemas por parte dos agricultores, o formato e tamanho das frutas, período de colheita etc. Outra parte da pesquisa estava relacionada à utilização do tipo de fibra mais adequado à mistura do compósito. Essa atividade estava sob a coordenação do IMA. A EMBRAPA atuou na Aliança 1 como intermediária do setor primário produtivo, fornecendo os resíduos da produção agrícola para serem utilizados como matéria-prima. Além disso, coube a ela, devido ao contato direto com o setor produtivo, o levantamento das necessidades de cada produto e das características apropriadas das embalagens; bem como a concessão de informações sobre as propriedades dos produtos, no que diz respeito à fisiologia póscolheita, vida útil, dimensões, temperatura e umidade relativa ao armazenamento.

A cultivar de cevada Quaranta também foi desenvolvida por meio de aliança estratégica para P\&D (Aliança 2, descrita na Tabela 2), com a participação de três instituições, EMBRAPA Trigo, Fundação Agrária de Pesquisa Agropecuária (FAPA) e a Companhia de Bebidas das Américas (AmBev). À EMBRAPA coube a realização de todo o processo de pesquisa para melhoramento genético de cevada, que abrange atividades de cruzamentos, avanço de gerações e seleção de progênies, a realização de testes de avaliação e de valor de cultivo, e uso VCU. Aos parceiros (AmBev e FAPA), ficaram designados: a realização de testes de avaliação de qualidade de malte e cerveja; a validação de desempenho agronômico de cultivares registradas em nome da EMBRAPA; os testes de avaliação e de VCU em linhagens desenvolvidas pela EMBRAPA. A atuação mais intensa dos parceiros está, portanto, na fase de desenvolvimento, na Aliança 2.

$O$ produto INOVA-Bti também foi desenvolvido por meio de aliança estratégica de P\&D (Aliança 3, descrita na Tabela 2) entre a EMBRAPA Recursos Genéticos e Biotecnologia (CENARGEN), em parceria com o Instituto Mato-Grossense do Algodão (IMAmt) e a Cooperativa Mista de Desenvolvimento do Agronegócio (COMDEAGRO) (EMBRAPA, 2017). Dentre as atividades de P\&D da Aliança 3, estavam: indicação de estirpes (bactérias), otimização do processo de produção das estirpes, desenvolvimento de formulações de alta qualidade e avaliação da toxidade dos produtos. À EMBRAPA cabia: obter as autorizações necessárias para o cumprimento da legislação de acesso ao patrimônio genético; responsabilizar-se pelas atividades previstas no Plano de Trabalho; e disponibilizar as estirpes a serem utilizadas na execução desse contrato. Dentre as atividades do IMAmt, estavam: a disponibilização de recursos humanos para a execução do contrato, responsabilizando-se pelo pagamento das despesas; contratação de pesquisador; realização de compras (materiais de consumo e equipamentos) e contratação de serviços. As atividades da COMDEAGRO eram: obter as autorizações necessárias para regular o cumprimento da legislação de acesso ao patrimônio genético e responsabilizar-se pela gestão do processo de obtenção dos registros dos produtos que viessem a ser obtidos, junto às autoridades competentes, em especial à Agência Nacional de Vigilância Sanitária, incluindo as despesas decorrentes.

Institucionalização dos processos de CR

Com base na análise da CR, foi possível identificar, nas alianças estudadas, a presença de processos de coordenação interorganizacional, transformação da aliança, aprendizagem e proatividade, conforme estabelecido pelo modelo de capacidade relacional de Schilke e Goerzen (2010). No que diz respeito aos processos de coordenação, 
cabe destacar a utilização de planos de trabalho, em que estavam descritas as atividades de P\&D de cada um dos parceiros, a metodologia de trabalho, a previsão de recursos a serem investidos por cada uma das partes e o cronograma das atividades. Esses planos de trabalho foram elaborados a partir do compartilhamento de informações prévias dos recursos e conhecimentos de cada ator envolvido na aliança, e posterior divisão das atividades e responsabilidades de cada um. Além disso, cada ator designou um pesquisador para coordenar as atividades, sendo que os esforços foram direcionados ao cumprimento desses planos.

Além dos processos acima mencionados, na Aliança 1 (embalagens anatômicas para frutas), foi criado um comitê, composto por um pesquisador (designado) de cada instituição, que coordenava as atividades da sua instituição e, em conjunto com os demais, verificava o andamento das atividades de P\&D das outras instituições, garantindo a sincronia das atividades. Para tanto, aconteciam reuniões mensais, trocas de e-mails (sempre com cópia para todos), e relatórios técnicos e financeiros eram encaminhados semestralmente para a agência de fomento. Além disso, os representantes do comitê visitavam periodicamente os laboratórios de pesquisa, os fornecedores de matéria-prima e os produtores. O parceiro da Aliança 1 ficou responsável pelo controle financeiro, pela autorização de compras e viagens, além da prestação de contas da aliança.

A formação de comitês para avaliação da aliança, as reuniões para planejamento, as avaliações de resultados e a discussão compartilhada de estratégia são, portanto, considerados processos que contribuíram para a coordenação das alianças. É importante que haja mecanismos de sincronização, para conciliar os interesses individuais de cada instituição e para que ocorra o alinhamento das informações (Gofredo \& Bataglia, 2015) e práticas (Lorenzoni \& Lipparini, 1999) entre os parceiros, de modo a harmonizá-los na busca dos objetivos da aliança, contribuindo para uma eficiente coordenação (Gofredo \& Bataglia, 2015) e cocriação do conhecimento (Silva \& Rossi, 2018).

Na Aliança 2 (cultivar de cevada), os processos para coordenação das atividades e gestão da aliança se deram por meio de contato telefônico e constantes trocas de e-mails. Além disso, os parceiros se reuniam anualmente para a sincronização das informações. Nesse momento, eram relatadas as atividades já executadas e elaborado o planejamento das próximas atividades. Visitas aos experimentos, com a participação dos representantes de cada instituição parceira, também eram realizadas. A EMBRAPA tinha responsabilidade de dar início aos processos de renovação das alianças, contando com a manifestação de interesse e sugestões das partes.

$\mathrm{Na}$ Aliança 3 (inseticida biológico), foram designados, além do gestor técnico (pesquisador), um gestor administrativo, que realizou a avaliação do andamento das atividades, e um gestor para controle da vigência do instrumento. A sincronia das atividades se deu por meio de reuniões técnicas, avaliações e relatórios. O pesquisador do parceiro da aliança foi responsável por fazer a solicitação das compras dos materiais e equipamentos, a contratação de pessoas para a realização das atividades de $P \& D$ e a prestação de contas para sua instituição (parceiro). Foi possível constatar que houve um engajamento nos esforços de coordenação por meio de ações explícitas para ajustar as atividades dos parceiros, a fim de atingir metas determinadas conjuntamente, aumentando a qualidade relacional e a cooperação na aliança, o que contribuiu para os resultados (Estrada et al., 2016) e a cocriação de conhecimento (Silva \& Rossi, 2018).

A EMBRAPA apresentou proatividade somente na Aliança 1 , buscando parceiros em potencial para a complementação da sua expertise. Já nas Alianças 2 e 3, a EMBRAPA foi procurada por parceiros, em decorrência do conhecimento científico, experiência em P\&D e de seus recursos (laboratórios e materiais genéticos). Esses parceiros (Aliança 2 e 3 ) demonstraram atuar constantemente de forma proativa, uma vez que sempre buscam auxílio nas soluções de problemas e na demanda do mercado. A proatividade está relacionada à capacidade em reconhecer o contexto do ambiente, por meio da identificação da necessidade de clientes, dos segmentos de mercado-alvo, de uma nova oportunidade tecnológica ou do mercado (Teece, 2007) e, posteriormente, tomar a iniciativa de buscar parceiros em potencial para aquisição de recursos externos (Schilke \& Goerzen, 2010).

Os processos de aprendizagem estão relacionados à capacidade de transferir o conhecimento do parceiro da aliança para a instituição (Teece, 2007; Patterson \& Ambrosini, 2015). Foi possível constatar que houve troca de conhecimento científico e/ou de mercado 
entre as instituições parceiras. $\mathrm{Na}$ Aliança 1 (EMBRAPA e o IMA - não conectado), houve absorção, pela EMBRAPA, do conhecimento específico desse parceiro, detentor de expertise na área de polímeros, transferindo, em seguida, esse aprendizado a outros pesquisadores e às equipes de pesquisa, por meio de discussões, reuniões e apresentações técnicas, a fim de possibilitar que tal conhecimento pudesse ser utilizado em outros projetos da EMBRAPA. Por outro lado, o IMA absorveu o conhecimento técnico-científico na área de pós-colheita, transmitindo-o para os alunos, por meio da docência, e à equipe do laboratório. Essa aliança ainda resultou em patentes, publicações de artigos científicos e capítulos de livro, que são meios de transferência de conhecimento para a sociedade.

Na Aliança 2 (EMBRAPA, FAPA e AmBev), a EMBRAPA absorveu conhecimentos relacionados às demandas e exigências de mercado sobre a qualidade da cerveja e do malte, compreendendo as necessidades e a produção de determinadas regiões do estado do Paraná. Esse conhecimento foi transferido para a equipe, por meio de seminários e palestras. A instituição parceira, por sua vez, adquiriu conhecimento técnico da EMBRAPA acerca das culturas, controle de doenças, plantio direto e conservação do solo; e conhecimentos gerais, por meio dos dias de campo e Reuniões da Cevada. A transferência desse conhecimento se deu internamente, via treinamento dos técnicos.

$\mathrm{Na}$ Aliança 3, a EMBRAPA adquiriu conhecimento do processo de formulação e produção do produto. A transferência do conhecimento ocorreu internamente, por meio de seminários quinzenais para a apresentação do andamento dos projetos e de seus resultados. O parceiro dessa aliança adquiriu conhecimentos relacionados aos processos de pesquisa com microrganismos e controle biológicos. Muitos dos recursos buscados nas alianças são conhecimentos tácitos ou acesso ao know-how do parceiro (Dyer \& Singh, 1998). Ter desenvolvida a aprendizagem significa que uma instituição possui capacidade em adquirir, assimilar, transformar e explorar esses conhecimentos, melhorando, assim, seu desempenho (Zahra \& George, 2002).

Constatou-se que, ao longo da vigência das alianças, alterações foram necessárias, o que exigiu interação e adaptação entre os parceiros. Nesse sentido, é importante desenvolver processos de auxílio em casos de mudanças, durante o percurso das alianças
(Wang \& Rajagopalan, 2015). Na Aliança 1 , houve mudança de responsabilidade na submissão de patentes; além disso, foi preciso aumentar o quantitativo de moldes a serem desenvolvidos, levando a readequações financeiras e a alterações na ordem de produção das embalagens. Na Aliança 2, os ajustes de cláusulas contratuais e dos quantitativos de experimentos aconteceram no momento da renovação do contrato. A alteração, na Aliança 3, esteve relacionada aos ajustes do cronograma, em decorrência do atraso na instalação de equipamento comprado no exterior. A mudança nas alianças é considerada um fenômeno natural, por isso, é importante que as partes consigam efetivá-la em conjunto, ou ampliar as chances do desempenho satisfatório das alianças (Reuer \& Zollo, 2000).

O desenvolvimento de uma capacidade depende do aprimoramento de processos (Winter, 2003). Assim, quando instituições possuem estruturas organizacionais estabelecidas e pessoas especializadas, de modo que produzam resultados favoráveis, os processos de gestão das alianças estratégicas de P\&D estão institucionalizados (Crossan et al., 1999).

A partir da análise das três alianças, verificou-se que todas possuem processos da $\mathrm{CR}$ institucionalizados. As instituições adotam processos e mecanismos formalizados e replicáveis para a coordenação das alianças de P\&D (manuais, diretrizes, assessoria jurídica, departamentos e pessoas especializadas na formalização e gestão das alianças, softwares para acompanhamento das atividades internas, plano de atividades, setor para realizar prestação de contas, compras, contratação de pessoas). Elas demonstraram, ainda, capacidade de aprendizagem, a partir dos conhecimentos específicos das instituições parceiras ou daqueles gerados pela aliança e transferidos. A flexibilidade (transformação) para mudanças, bem como a existência de processos de proatividade foram verificados na EMBRAPA Agroindústria de Alimentos, FAPA e IMAmt; no entanto, tais processos não se mostraram sistematizados na EMBRAPA Trigo, EMBRAPA CENARGEN e IMA, como está destacado na Tabela 3 (proposição não aderente). 
Tabela 3. Análise das proposições atreladas à institucionalização dos processos de CR.

\begin{tabular}{|c|c|c|c|}
\hline \multirow[b]{2}{*}{$\begin{array}{l}\text { Proposições atreladas à } \\
\text { institucionalização dos } \\
\text { processos de CR }\end{array}$} & \multicolumn{3}{|c|}{ Aderência frente às proposições levantadas } \\
\hline & $\begin{array}{c}\text { Aliança (1) } \\
\text { Embalagens anatômicas para } \\
\text { frutas }\end{array}$ & $\begin{array}{c}\text { Aliança (2) } \\
\text { Cultivar de cevada - BRS } \\
\text { Quaranta }\end{array}$ & $\begin{array}{c}\text { Aliança (3) } \\
\text { INOVA-Bti - inseticida } \\
\text { biológico }\end{array}$ \\
\hline
\end{tabular}

\section{ADERENTE ADERENTE}

Estabelecimento de Plano de Trabalho, com atividades de P\&D, metodologia de trabalho, previsão de recursos, cronograma das atividades. Foi designado um Coordenação pesquisador de cada instituição interorganiza- para coordenação das atividades; cional

(P1) À medida que as organizações institucionalizam os processos de coordenação interorgani-zacional proatividade em aliança, aprendizagem organiza cio-nal e transformação das alianças, mais madura será a capacidade relacional.

criação de comitê para o acompanhamento das atividades, reuniões mensais, troca de e-mails, elaboração de relatórios técnicos e financeiros; visitas aos laboratórios de pesquisa, fornecedores de matéria-prima e produtores.

$\begin{array}{ll}\text { ADERENTE } \\ \begin{array}{ll}\text { Proatividade na } \\ \text { aliança }\end{array} & \begin{array}{l}\text { EMBRAPA buscou parceiros em } \\ \text { potencial para complementação da } \\ \text { expertise. }\end{array}\end{array}$
instrumento.

\section{NÃO ADERENTE} de Plano de P\&D, metodologia de trabalho, previsão de recursos, cronograma das atividades. Foi designado um pesquisador de cada instituição para coordenação das atividades; a coordenação era realizada por contato telefônico, troca de e-mails, reunião anual com a elaboração de relatório e visita técnica aos experimentos; um empregado da EMBRAPA foi responsável pelo processo de renovação do

foi procurada pelos EMBRAPA foi procurada pelos do conhecimento científico, do conhecimento científico, experiência em P\&D e seus recursos experiência em P\&D e seus recursos (laboratórios, materiais genéticos). (laboratórios, materiais genéticos).

\section{ADERENTE}

Absorção de conhecimento técnicocientífico na área de polímeros e pós-colheita; transferência do conhecimento para equipes de pesquisa, por meio de discussões, reuniões e apresentações técnicas; para os alunos, por meio da docência; e para equipe do laboratório; publicações de artigos científicos, capítulos de livros e registro de patentes.
Aprendizagem d e c orrent e da troca conhecimento na aliança

\section{ADERENTE}

Alteração da responsabilidade de Transformação submissão de patentes; alteração da aliança no quantitativo de moldes de embalagens; adequaçõe financeiras e cronológicas.

\section{ADERENTE}

Absorção de conhecimento mercadológico sobre a qualidade da cerveja e do malte; compreensão da demanda e necessidade do mercado; aquisição do conhecimento das necessidades e produção de regiões específicas; conhecimento técnico-científico acerca do desenvolvimento de cultivares, controle de doenças, plantio direto, conservação do solo; conhecimento transferido por meio de palestras, seminários, dias de campo, treinamento e reunião da cevada.
Estabelecimento de plano de trabalho, com atividades de P\&D, metodologia de trabalho, previsão de recursos, cronograma das atividades. Foi designado um pesquisador de cada instituição, para coordenação das atividades; um gestor administrativo do contrato, para avaliação do andamento das atividades; e um gestor para controle da vigência. Houve realização de reuniões, iaçoes técnicas e relatorios determinado o parceiro responsável ela aquisição de materiais, equipamentos e contratação de pessoas para atividades de P\&D.

\section{ADERENTE}

Absorção de conhecimento de formulação e produção; conhecimento relacionado aos processos de pesquisa com microrganismos biológicos e controle biológico; transferência de conhecimento por meio de seminários.

Nota. Fonte: Elaborada pelos autores, com base nos dados da pesquisa.

\section{Transbordamentos da capacidade relacional}

Alianças orientadas para competência são movidas pelo desejo das instituições em aprimorar seus recursos internos (pelo acesso a recursos complementares) e o conhecimento interno (pela aprendizagem organizacional e criação de conhecimento) (Lin \& Darnall, 2015). Com isso, as instituições são mais propensas a buscar parceiros diversificados e intersetoriais (empresas, universidades, institutos de pesquisa, fornecedores, clientes etc.) (Walsh et al., 2016).
Constatou-se, nas três alianças estudadas, que cada instituição parceira possuía conhecimentos e recursos específicos, sendo motivadas a estabelecer alianças para agregar ativos, capacidades e habilidades distintas e complementares para o alcance dos objetivos. Tanto nas unidades da EMBRAPA investigadas e nos parceiros não conectados ao mercado (IMA e IMAmt), verificou-se uma expertise na realização de atividades de pesquisas, como no parceiro da Aliança 1 (embalagens anatômicas), o IMA, que é um instituto especializado na pesquisa de polímeros. Por outro lado, os parceiros conectados 
ao mercado (AmBev e COMDEAGRO) possuem um conhecimento maior sobre ele, uma vez que estão sempre em busca do desenvolvimento de inovações para atender à demanda. Verificou-se que, a partir dessas alianças, houve o transbordamento de processos de uma instituição para a outra (da empresa pública de pesquisa, para parceiros conectados ou não conectados) e de desenvolvimento (dos parceiros conectados ou não ao mercado, para a empresa pública de pesquisa), resultando em aprimoramento ou novas práticas.

Na Aliança 1, a partir do conhecimento adquirido da EMBRAPA Agroindústria de Alimentos, relacionado aos processos inerentes às pesquisas de pós-colheita, a instituição parceira (IMA) desenvolveu uma linha de pesquisa de embalagens com estabelecimento do fluxo do processo (transbordamento de processos das instituições não conectadas ao mercado para os parceiros não conectados - EMBRAPA e IMA).

Na Aliança 2, a partir dos conhecimentos inerentes às atividades de pesquisa da FAPA e da instituição mercadológica da AmBev, a EMBRAPA adaptou metodologia de P\&D para desenvolvimento de cevada e outros cereais, decorrente dos conhecimentos da demanda da indústria, como qualidade do malte (AmBev) e de clima, e sobre os produtores de regiões do Paraná, obtidos na FAPA. De acordo com o parceiro FAPA, da Aliança 2, no início da parceria com a EMBRAPA, $100 \%$ dos cultivares de cevada utilizados eram decorrentes de alianças com aquela empresa. Hoje, a instituição já utiliza 50\% delas, que são desenvolvidas em alianças com outras instituições. Além disso, constatou-se que a instituição adaptou as cláusulas contratuais, conforme modelos adotados nas pesquisas conduzidas pela EMBRAPA. Assim, é possível inferir que, a partir dessa aliança, a instituição passou a utilizar processos da EMBRAPA para a realização de P\&D (transbordamento de processos da empresa pública de pesquisa para o parceiro não conectado EMBRAPA - FAPA).

$\mathrm{Na}$ Aliança 3, a partir das dificuldades encontradas junto aos órgãos regulamentadores para a produção desse tipo de produto, a EMBRAPA desenvolveu um documento regulatório de requisitos essenciais à formação de alianças para o desenvolvimento de produtos similares. Como o parceiro possui a expertise na formulação e na produção, a EMBRAPA incorporou, adaptou e passou a utilizar processos de formulação e produção de produtos similares (transbordamento de processos das instituições conectadas ao mercado para as não conectadas - COMDEAGRO e EMBRAPA). O COMDEAGRO, por sua vez, construiu a fábrica para a produção do bioinseticida com base no conhecimento e processos já realizados, devido à expertise apreendida na EMBRAPA CENARGEN, em biotecnologia. Inclusive, os empregados do parceiro realizaram treinamentos dentro da EMBRAPA (transbordamento de processos das instituições não conectadas ao mercado para as conectadas EMBRAPA e COMDEAGRO).

A Tabela 4 apresenta a análise do transbordamento de processos de P\&D, de acordo com o parceiro. Vale enfatizar que o modelo de capacidade relacional de Schilke e Goerzen (2010) estabelece os processos: coordenação interorganizacional, transformação da aliança e aprendizagem e proatividade.

Tabela 4. Análise das proposições atreladas aos transbordamentos da CR.

\begin{tabular}{|c|c|c|c|}
\hline \multirow[b]{2}{*}{$\begin{array}{l}\text { Proposições atreladas aos } \\
\text { transbordamentos da CR }\end{array}$} & \multicolumn{3}{|c|}{ Aderência frente às proposições levantadas } \\
\hline & $\begin{array}{l}\text { Aliança (1) } \\
\text { Embalagens anatômicas para } \\
\text { frutas: uma inovação de } \\
\text { processo }\end{array}$ & $\begin{array}{c}\text { Aliança (2) } \\
\text { Cultivar de cevada - BRS } \\
\text { Quaranta: uma inovação de } \\
\text { produto }\end{array}$ & $\begin{array}{c}\text { Aliança (3) } \\
\text { INOVA-Bti - inseticida } \\
\text { biológico: uma inovação de } \\
\text { produto }\end{array}$ \\
\hline $\begin{array}{l}\text { (P2) Em alianças estratégicas } \\
\text { de P\&D, processos inerentes à } \\
\text { pesquisa são transbordados da } \\
\text { empresa pública de pesquisa } \\
\text { para os parceiros (conectados } \\
\text { ou não conectados). }\end{array}$ & $\begin{array}{c}\text { ADERENTE } \\
\text { Desenvolvimento no IMA de } \\
\text { uma linha de pesquisa de } \\
\text { embalagens com adoção de } \\
\text { processos de pesquisa da } \\
\text { EMBRAPA. }\end{array}$ & $\begin{array}{c}\text { ADERENTE } \\
\text { FAPA diversificou a pesquisa } \\
\text { e a fonte de cultivares de } \\
\text { cevada e adaptou as cláusulas } \\
\text { contratuais, conforme modelos } \\
\text { adotados nas pesquisas } \\
\text { conduzidas pela EMBRAPA. }\end{array}$ & $\begin{array}{c}\text { ADERENTE } \\
\text { COMDEAGRO construiu uma } \\
\text { fábrica para a produção do } \\
\text { bioinseticida, com base na } \\
\text { orientação em pesquisa e } \\
\text { treinamentos concedidos pela } \\
\text { EMBRAPA. }\end{array}$ \\
\hline $\begin{array}{c}\text { (P3) Em alianças estratégicas } \\
\text { de P\&D, processos inerentes } \\
\text { ao desenvolvimento são } \\
\text { transbordados dos parceiros } \\
\text { (conectados ou não ao mercado) } \\
\text { para a empresa pública de } \\
\text { pesquisa. }\end{array}$ & $\begin{array}{c}\text { NÃO SE APLICA } \\
\text { Aliança celebrada com } \\
\text { instituição não conectada ao } \\
\text { mercado, com expertise em } \\
\text { pesquisa de polímeros. }\end{array}$ & $\begin{array}{c}\text { ADERENTE } \\
\text { Adaptação na EMBRAPA da } \\
\text { metodologia de P\&D para } \\
\text { desenvolvimento de cevadas, } \\
\text { decorrente dos conhecimentos } \\
\text { da demanda da indústria } \\
\text { (AmBev) e de clima e produtores } \\
\text { de regiões do Paraná, obtidos } \\
\text { na FAPA. }\end{array}$ & $\begin{array}{c}\text { ADERENTE } \\
\text { Utilização, na EMBRAPA, de } \\
\text { processos de formulação e } \\
\text { produção de produtos similares, } \\
\text { que eram de expertise do } \\
\text { parceiro, COMDEAGRO. }\end{array}$ \\
\hline
\end{tabular}

Nota. Fonte: Elaborada pelos autores, com base em dados da pesquisa. 


\section{MODELO INTERORGANIZACIONAL PROPOSITIVO}

Com base no estudo em profundidade das alianças geradoras de inovações agropecuárias (como o desenvolvimento de embalagens anatômicas para frutas, da cultivar de cevada cervejeira BR Quaranta e do bioinseticida INOVA-Bti), foi possível o desenvolvimento de um modelo interorganizacional propositivo, a partir de um confronto teórico-empírico, envolvendo uma empresa pública de pesquisa e seus parceiros conectados e não conectados ao mercado (Figura 1).

O modelo é dividido em quatro blocos, que representam as categorias de análise da CR evidenciadas empiricamente, incluindo: (Bloco 1) Maturidade da CR; (Bloco 2) Transbordamento da CR; (Bloco 3) Resultados; e (Bloco 4) Facilitador (Figura 1).

O Bloco 1, com base nas evidências empíricas, indica que quanto mais institucionalizado é um dado conjunto de processos de gestão estratégica de alianças de P\&D em uma empresa pública de pesquisa, mais madura (institucionalizada) seráa $\mathrm{CR}$, cujos processos constitutivos tornam-se passíveis de replicação e adaptação em alianças futuras (Figura 1).

Especificamente, pode-se evidenciar um conjunto de processos capazes de conferir a maturidade da CR, que estão discriminados a seguir.

(a) Processos de coordenação interorganizacional: estabelecimento de plano de trabalho de P\&D, com detalhamento do método, da previsão de recursos e do cronograma das atividades; designação formal de colaboradores das instituições parceiras para coordenação das atividades; criação de comitê para o acompanhamento das atividades; elaboração de relatórios técnicos e financeiros dos projetos para avaliação dos resultados; e visitas aos laboratórios de pesquisa, fornecedores de matéria-prima e produtores.

(b) Processos de proatividade na aliança: busca por parceiros com potencial para complementação da expertise em P\&D e pela disponibilidade de recursos, incluindo laboratórios e materiais genéticos.

(c) Aprendizagem: absorção de conhecimento técnico-científico; compreensão da demanda e necessidade do mercado em regiões específicas; e disseminação do conhecimento por meio de palestras, seminários, dias de campo, treinamento, reuniões, publicações técnicas e científicas, capítulos de livros e registro de patentes.

(d) Transformação: realização de ajustes nas atividades de pesquisa no decorrer dos projetos; atualização de cláusulas contratuais e de valores financeiros realizados na renovação dos contratos de P\&D; alteração da responsabilidade de submissão de patentes; e adequações no cronograma de atividades.

Quando uma das instituições consegue desenvolver e, por conseguinte, institucionalizar esse conjunto de processos de gestão estratégica de alianças de P\&D, conferindo a maturidade da $\mathrm{CR}$, há transbordamento de processos de pesquisa e desenvolvimento entre a empresa pública de pesquisa e os parceiros conectados e não conectados ao mercado (Figura 1).

Particularmente, sobre os processos de transbordamento (Bloco 2), nota-se que, em alianças com ambos os escopos (pesquisa e desenvolvimento), há o transbordamento de processos de pesquisa da empresa pública de pesquisa (devido à expertise científica) para o parceiro (tanto conectado quanto não conectado ao mercado). Por outro lado, no caso de processos de desenvolvimento, há transbordamentos de ambos os parceiros (conectados e não conectados) para a empresa pública de pesquisa, resultando no aprimoramento de processos ou na adoção de novas práticas de desenvolvimento (Figura 1). Sendo assim, foi possível evidenciar o transbordamento dos seguintes processos de P\&D, a saber:

(a) Transbordamento de processos de desenvolvimento: (1) diversificação de produtos e processos já existentes na empresa pública, referência em pesquisa, após o estabelecimento de aliança com parceiro mais conectado às necessidades regionais; (2) adoção de novos padrões de desenvolvimento da qualidade na empresa pública, referência em pesquisa, após o estabelecimento de aliança com parceiro mais conectado às necessidades industriais; (3) implementação de documento regulatório de requisitos essenciais à P\&D, colaborativo na empresa pública, referência em pesquisa, após o estabelecimento de aliança com parceiro de maior expertise em salvaguardas contratuais;

(b) Transbordamento de processos de pesquisa: (1) implementação de uma nova linha de pesquisa no parceiro, após o estabelecimento de alianças com empresa pública, referência em pesquisa; (2) após o estabelecimento de alianças com empresa pública, referência em pesquisa, há incorporação, por parte do parceiro, de processos de pesquisa que viabilizam, por conseguinte, a implementação de fábrica para produção de produto inovador; (3) após as alianças, os funcionários do parceiro continuam a realizar treinamentos em pesquisa na empresa pública, referência em pesquisa.

Pode-se concluir, a partir dos Blocos 1 e 2 do modelo interdisciplinar propositivo, que a CR potencializa o desenvolvimento de produtos, processos, patentes etc. e, posteriormente, inovações para o mercado. No modelo (Figura 1), ainda representa que, se os produtos, processos e patentes forem desenvolvidos em alianças nas quais há pelo menos um parceiro mercadológico (por exemplo, uma empresa ou indústria), eles mais rapidamente serão disponibilizados no mercado para comercialização, transformando-se em inovações, isso porque parceiros mercadológicos possuem maior expertise em comercialização, ou seja, na geração de inovações. 


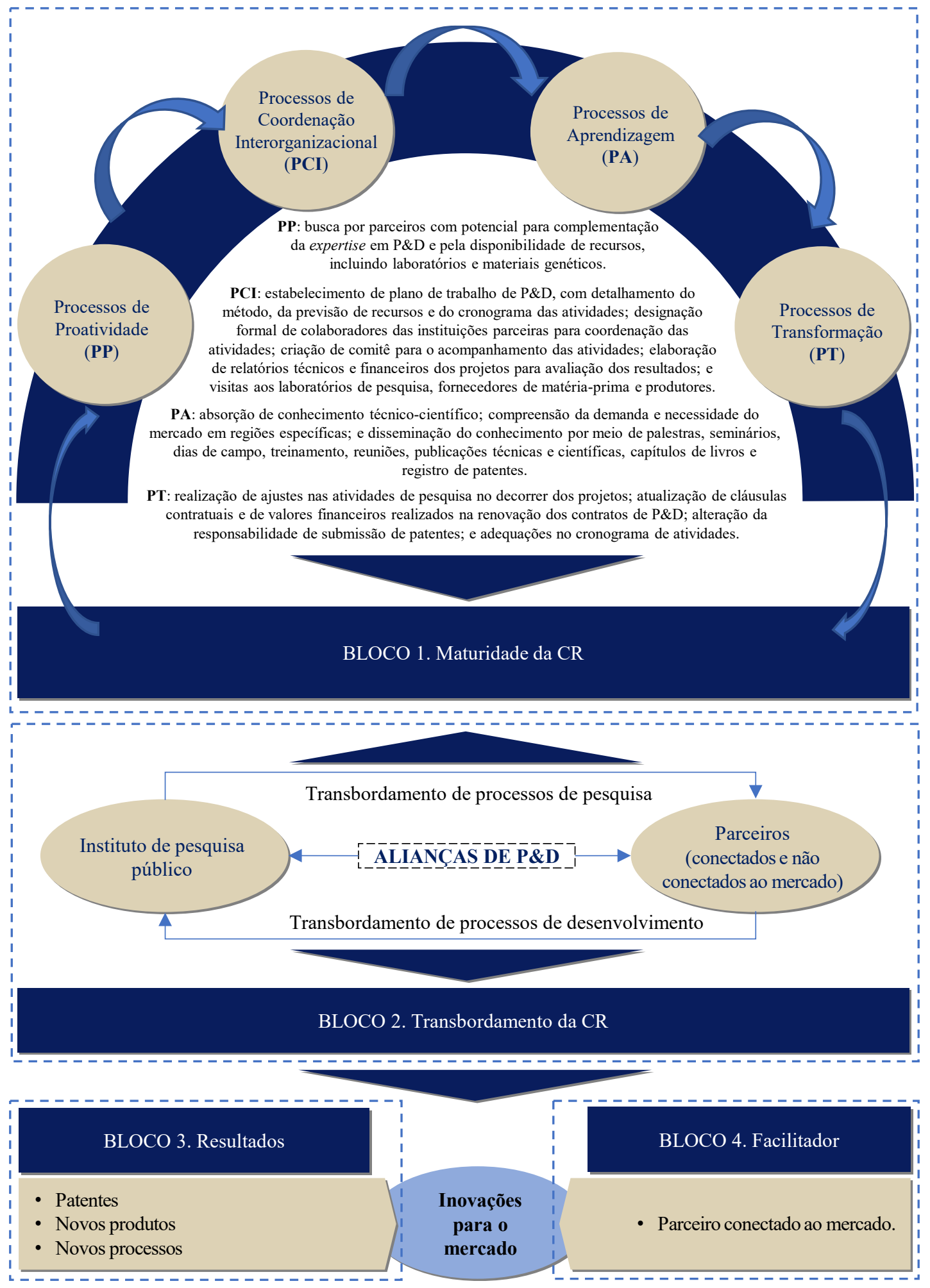

Figura 1. Modelo interorganizacional para geração de inovações a partir de alianças estratégicas de P\&D, fundamentado nas evidências empíricas dos processos da CR da EMBRAPA e dos seus parceiros externos.

Fonte: Elaborada pelos autores, com base nos dados da pesquisa. 
Vale, por fim, enfatizar que o modelo de CR de Schilke e Goerzen (2010), adotado por este estudo como base teórica, é fundamentado nas seguintes categorias de análise: coordenação interorganizacional, transformação da aliança, aprendizagem, proatividade em alianças e portfólio de alianças. Esta última não foi considerada, visto que o foco do estudo foram as alianças díades e não o portfólio. Por sua vez, o modelo interorganizacional proposto (Figura 1) evidencia, de forma inédita, os processos de institucionalização e de transbordamento da CR, ou seja, gera uma contribuição distintiva e ampliada ao campo da capacidade relacional em alianças estratégicas de $\mathrm{P} \& \mathrm{D}$, comparativamente ao modelo de Schilke e Goerzen (2010), pois fornece mais clareza sobre como uma empresa pública de pesquisa institucionaliza e transborda processos de capacidade relacional em alianças de P\&D interorganizacionais (não contempladas no modelo de Schilke e Goerzen (2010).

\section{CONSIDERAÇÕES FINAIS}

Foi constatado que, quando as instituições possuem e desenvolvem as dimensões e fatores potencializadores da $\mathrm{CR}$, ocorre transbordamento de processos inerentes à pesquisa e ao desenvolvimento entre a EMBRAPA e os parceiros externos envolvidos nas alianças estratégicas de P\&D. Mais especificamente, em alianças com ambos os escopos, pesquisa e desenvolvimento, houve o transbordamento de processos de pesquisa da EMBRAPA (devido à expertise científica) para o parceiro (conectado ou não ao mercado); e do parceiro (conectado ou não ao mercado) para a EMBRAPA, no caso de processos de desenvolvimento, resultando no aprimoramento desses processos ou na adoção de novas práticas.

$E$, finalmente, verificou-se que as unidades da EMBRAPA e parceiros externos possuem as dimensões de coordenação, aprendizagem e transformação da CR institucionalizadas (formalizadas e passíveis de replicação em alianças futuras). Com relação à proatividade, também integrante do construto $C R$, ela foi apresentada por uma unidade da EMBRAPA (Agroindústria de Alimentos) e dois parceiros (FAPA e IMAmt). Pode-se considerar que essas instituições possuem essas dimensões amadurecidas de modo geral, ou seja, formalizadas e, portanto, passíveis de replicação em alianças futuras.

Quanto ao aspecto econômico da inovação, as embalagens anatômicas para frutas ainda devem ser potencializadas, no que tange à inserção no mercado e comercialização. Constatou-se que o principal motivo para isso não ter ainda acontecido foi a ausência de um parceiro mercadológico, desde as fases iniciais de P\&D. Quando não se tem a participação de instituições conectadas ao mercado (empresas, indústrias ou cooperativas) desde o princípio, fica mais difícil, posteriormente, o convencimento de que se trata de um produto ou processo que serábem aceito pelo mercado, ou, ainda, que o percentual de royalties a ser pago é um valor adequado em relação ao investimento. Nas demais alianças analisadas (cultivar de cevada cervejeira e inseticida biológico), constatou-se a existência de uma conexão com o mercado, decorrente da aliança com parceiros que nele atuam, como cooperativas e indústrias, o que justifica o fato de as inovações decorrentes dessas alianças já promoverem impacto econômico, social e ambiental.

Este estudo contribui para o avanço do conhecimento relacionado às alianças de $\mathrm{P} \& \mathrm{D}$, especificamente, no que diz respeito à institucionalização e ao transbordamento de processos, culminando em um framework propositivo. Em alianças de P\&D, quando os parceiros possuem a CR desenvolvida, eles conseguem transbordar conhecimentos e processos de pesquisa (instituto de pesquisa público para o parceiro) e de desenvolvimento (parceiro para o instituto de pesquisa público), passando a aprimorar seus próprios processos ou a adotar novas práticas. Da mesma forma, quanto mais institucionalizados estão os processos da CR, mais amadurecida ela será, sendo passível de replicação por outras alianças.

Para os gestores de instituições de P\&D, conectados ou não ao mercado, o estudo indica que, quando alianças de P\&D forem formadas, com ênfase no desenvolvimento de inovações, os parceiros reincidentes de outras alianças poderão potencializar a $\mathrm{CR}$, levando ao desenvolvimento da inovação de forma mais ágil. Por outro lado, quando instituições não conectadas ao mercado buscam parceiros para alianças de P\&D, com ênfase no desenvolvimento de inovações, é importante que, entre os parceiros, seja incluído pelo menos um que esteja conectado ao mercado, com potencial capacidade de produção futura. Dessa forma, é importante que os gestores atuem ativamente na escolha dos parceiros, de acordo com a ênfase da aliança, de modo a atingir os objetivos e melhores resultados com a aliança.

Apesar de terem sido encontrados indícios que comprovem a coordenação eficiente dessas alianças, apresenta-se como sugestão (prática já comprovada na literatura) aos gestores, a adoção (por parte de todos os parceiros) de mecanismos para uma gestão mais integrada, com a utilização de softwares e intranet, para planejamento conjunto e gestão (Hoang \& Rothaermel, 2005) das alianças. As instituições também podem formar internamente equipes e/ou comitês para auxiliarem na gestão 
formalizada das alianças (administrativa e de coordenação), de modo a centralizar as informações e a experiência, permitindo que elas sejam utilizadas em alianças futuras, e para fazer acompanhamento nas fases inicial, intermediária e final das atividades desenvolvidas.

Devido à pesquisa ser qualitativa, a seleção do número de casos é restrita e limitante, não sendo possível a sua generalização para outras alianças de $\mathrm{P} \& \mathrm{D}$, para o desenvolvimento de inovação, nem seus resultados em relação às outras unidades da EMBRAPA e de seus parceiros.

Foi possível, ainda, identificar que, em alianças de P\&D para desenvolvimento de inovações agropecuárias, os pesquisadores tanto da EMBRAPA quanto dos parceiros, que atuam diretamente

\section{REFERÊNCIAS}

Almeida, J. M. S. de, \& Costa, P. R. da (2017). Development of relational capability in technology-based companies in the information and communication technology sector. International Journal of Managerial Studies and Research, 5(4), 119-126. https://doi.org/10.20431/2349-0349.0504015

Appio, F. P., Martini, A., Petruzzelli, A. M., Neirotti, P., \& Van Looy, B. (2017). Search mechanisms and innovation: An analysis across multiple perspectives. Technological Forecasting And Social Change, 120, 103-116. https://doi.org/10.1016/j. techfore.2017.04.008

Barney, J. (1991). Firm resources and sustained competitive advantage. Journal of Management, 17(1), 99-120. http:// dx.doi.org/10.1177/014920639101700108

Bleeke, J., \& Ernst, D. (1991). The way to win in cross-border alliances. Harvard Business Review, 69(6), 127-135. Retrieved from https://hbr.org/1991/11/the-way-to-win-in-cross-borderalliances

Costa, P. R., \& Porto, G. S. (2014). Governança tecnológica e cooperabilidade nas multinacionais brasileiras. Revista de Administração de Empresas, 54(2), 201-221. Retrieved from https://rae.fgv.br/rae/vol54-num2-2014/governancatecnologica-cooperabilidade-nas-multinacionais-brasileiras

Creswell, J. W. (2017). Research design: Qualitative, quantitative, and mixed methods approaches. London: SAGE publications.

Crossan, M. M., Lane, H. W., \& White, R. E. (1999). An organizational learning framework: From intuition to institution. Academy of Management Review, 24(3), 522-537. http://dx.doi. org/10.2307/259140 nas atividades de $P \& D$, exercem papel importante na coordenação das atividades e nas relações interorganizacionais. Eles são canais pelos quais as alianças se formam, pois elas surgem a partir de sua rede de contato e em razão da experiência individual em alianças, o que também contribui para o seu êxito. Assim, estudos futuros poderiam analisar a influência da CR individual sobre a CR da instituição, em alianças estratégicas para a realização de P\&D, com fins de gerar inovações agropecuárias. Como futuras pesquisas, ainda, sugere-se a ampliação da análise, a partir de um número maior de instituições que celebram alianças estratégicas de P\&D na agropecuária.

Donada, C., Nogatchewsky, G., \& Pezet, A. (2016). Understanding the relational dynamic capability-building process. Strategic Organization, 14(2), 93-117. https://doi. org/10.1177/1476127015615286

Dyer, J. H., \& Singh, H. (1998). The relational view: Cooperative strategy and sources of interorganizational competitive advantage. Academy of Management Review, 23(4), 660679. https://doi.org/10.2307/259056

Empresa Brasileira de Pesquisa Agropecuária (2017). Embrapa em números. Retrieved from https://www.embrapa.br/ embrapa-em-numeros.

Estrada, I., Faems, D., Cruz, N. M., \& Santana, P. P. (2016). The role of interpartner dissimilarities in industryuniversity alliances: Insights from a comparative case study. Research Policy, 45(10), 2008-2022. https://doi. org/10.1016/j.respol.2016.07.005

Etzkowitz, H. (2017). Innovation Lodestar: The entrepreneurial university in a stellar knowledge firmament. Technological Forecasting and Social Change, 123, 122129. https://doi.org/10.1016/j.techfore.2016.04.026

Food and Agriculture Organization (2016). The state of food and agriculture 2016 (SOFA): Climate change, agriculture and food security. Food and agriculture organization of the United Nations. Retrieved from http://www.fao. org/3/a-i6030e.pdf.

Godoy,A.S.(1995). Introduçãoà pesquisa qualitativa e suas possibilidades. Revista de Administração de Empresas, 35(2), 57-63. Retrieved from https://rae.fgv.br/rae/vol35-num2-1995/introducaopesquisa-qualitativa-suas-possibilidades 
Gofredo,T.R.,\&Bataglia,W.(2015).Osmecanismosdesincronização em alianças estratégicas. Revista de Administração da Universidade Federal de Santa Maria, 8(4), 633-649. https://doi.org/10.5902/1983465911111110648

Gulati, R., Lawrence, P. R., \& Puranam, P. (2005). Adaptation in vertical relationships: Beyond incentive conflict. Strategic Management Journal, 26(5), 415-440. https:// doi.org/10.1002/smj.458

Heimeriks, K. H., \& Duysters, G. (2007). Alliance capability as a mediator between experience and alliance performance: An empirical investigation into the alliance capability development process. Journal of Management Studies, 44(1), 25-49. https://doi.org/10.1111/j.14676486.2006.00639.x

Helfat, C. E., Finkelstein, S., Mitchell, W., Peteraf, M., Singh, H., Teece, D., \& Winter, S. G. (2009). Dynamic capabilities: Understanding strategic change in organizations. New York: John Wiley \& Sons.

Hoang, H., \& Rothaermel, F. T. (2005). The effect of general and partner-specific alliance experience on joint R\&D project performance. Academy of Management Journal, 48(2), 332-345. https://doi.org/10.5465/amj.2005.16928417

Kale, P., Dyer, J. H., \& Singh, H. (2002). Alliance capability, stock market response, and long-term alliance success: The role of the alliance function. Strategic Management Journal, 23(8), 747-767. https://doi.org/10.1002/ smj. 248

Klotzle, M. C. (2002). Alianças estratégicas: Conceito e teoria. Revista de Administração Contemporânea, 6(1), 85-104. http://dx.doi.org/10.1590/S141565552002000100006

Lhuillery, S., \& Pfister, E. (2009). R\&D cooperation and failures in innovation projects: Empirical evidence from French CIS data. Research Policy, 38(1), 45-57. https://doi. org/10.1016/j.respol.2008.09.002

Lin, H., \& Darnall, N. (2015). Strategic alliance formation and structural configuration. Journal of Business Ethics, 127(3), 549-564. http://dx.doi.org/10.1007/s10551014-2053-7

Lorenzoni, G., \& Lipparini, A. (1999). The leveraging of interfirm relationships as a distinctive organizational capability: A longitudinal study. Strategic Management Journal, 20(4), 317-338. https://doi.org/10.1002/(SICI)10970266(199904)20:4<317::AID-SMJ28>3.0.CO;2-3

Lundvall, B. A. (1988). Innovation as an interactive process: From user-producer interaction to the National System of Innovation. In G. Dosi, C. Freeman, R. Nelson, G. Silverberg \& L. Soete (Eds.), Technical change and economic theory (Chapter 11, pp. 349-369). London: Pinter Publishers.

Milagres, R., Rezende, O., \& Silva, S. A. G. da (2017). Papel e posição do departamento de alianças: Caso Embrapa. Revista de Administração Pública, 51(3), 431-450. http://dx.doi.org/10.1590/0034-7612160046

Nehring, R. (2016). Yield of dreams: Marching west and the politics of scientific knowledge in the Brazilian Agricultural Research Corporation (Embrapa). Geoforum, 77, 206217. https://doi.org/10.1016/j.geoforum.2016.11.006
Niesten, E., \& Jolink, A. (2015). The impact of alliance management capabilities on alliance attributes and performance: A literature review. International Journal of Management Reviews, 17(1), 69-100. https://doi.org/10.1111/ ijmr. 12037

Ortiz-de-Urbina-Criado, M., Montoro-Sánchez, Á., \& MoraValentín, E.-M. (2014). Impact of growth strategy on mode of governance in alliances. International Business Review, 23(4), 838-848. https://doi.org/10.1016/j. ibusrev.2014.01.002

Patterson, W., \& Ambrosini, V. (2015). Configuring absorptive capacity as a key process for research intensive firms. Technovation, 36-37, 77-89. https://doi.org/10.1016/j. technovation.2014.10.003

Powell, W. W. (1987). Hybrid organizational arrangements: New form or transitional development? California Management Review, 30(1), 67-87. https://doi. org/10.2307/41165267

Powell, W. W., Koput, K. W., \& Smith-Doerr, L. (1996). Interorganizational collaboration and the locus of innovation: Networks of learning in biotechnology. Administrative Science Quarterly, 41(1), 116-145. https://doi.org/10.2307/2393988

Reuer, J., \& Zollo, M. (2000). Managing governance adaptations in strategic alliances. European Management Journal, 18(2), 164-172. https://doi.org/10.1016/S02632373(99)00088-2

Schilke, O., \& Cook, K. S. (2015). Sources of alliance partner trustworthiness: Integrating calculative and relational perspectives. Strategic Management Journal, 36(2), 276297. https://doi.org/10.1002/smj.2208

Schilke, O., \& Goerzen, A. (2010). Alliance management capability: An investigation of the construct and its measurement. Journal of Management, 36(5), 1192-1219. https://doi. org/10.1177/0149206310362102

Schut, M., Klerkx, L., Sartas, M., Lamers, D., Mc Campbell, M., Ogbonna, I., Kaushik, P., Atta-Krah, K., \& Leeuwis, C. (2016). Innovation platforms: Experiences with their institutional embedding in agricultural research for development. Experimental Agriculture, 52(4), 537561. https://doi.org/10.1017/S001447971500023X

Shakeri, R., \& Radfar, R. (2017). Antecedents of strategic alliances performance in biopharmaceutical industry: A comprehensive model. Technological Forecasting and Social Change, 122, 289-302. https://doi.org/10.1016/j. techfore.2016.01.003

Silva, M. de, \& Rossi, F. (2018). The effect of firms' relational capabilities on knowledge acquisition and co-creation with universities. Technological Forecasting and Social Change, 133, 72-84. https://doi.org/10.1016/j. techfore.2018.03.004

Sorrentino, F., \& Garraffo, F. (2012). Explaining performing R\&D through alliances: Implications for the business model of Italian dedicated biotech firms. Journal of Management \& Governance, 16(3), 449-475. https://doi.org/10.1007/ s10997-010-9159-9 
Teece, D. J. (2007). Explicating dynamic capabilities: The nature and microfoundations of (sustainable) enterprise performance. Strategic Management Journal, 28(13), 1319-1350. https:// doi.org/10.1002/smj.640

Walsh, J. P., Lee, Y.-N., \& Nagaoka, S. (2016). Openness and innovation in the US: Collaboration form, idea generation and implementation. Research Policy, 45(8), 1660-1671. https://doi.org/10.1016/j.respol.2016.04.013

Wang, Y., \& Rajagopalan, N. (2015). Alliance capabilities review and research agenda. Journal of Management, 41(1), 236-260. https://doi.org/10.1177/0149206314557157

Winter, S. G. (2003). Understanding dynamic capabilities. Strategic Management Journal, 24(10), 991-995. http://dx.doi. org/10.1002/smj.318

\section{Autores}

\section{Taísa Scariot Preusler}

Rua Vergueiro, nº 235/249, Liberdade, 01504-001, São Paulo, SP, Brasil.

E-mail: taisa.s@hotmail.com

ㄴ) https://orcid.org/0000-0002-0136-9040

\section{Priscila Rezende da Costa*}

Rua Vilela, nº 750, Tatuapé, 01156-050, São Paulo, SP, Brasil.

E-mail: priscilarezende@yahoo.com.br

(1) https://orcid.org/0000-0002-7012-0679

\section{Tatiane Baseggio Crespi}

Rua Vergueiro, no 235/249, Liberdade, 01504-001, São Paulo, SP, Brasil.

E-mail: tatianebaseggiocrespi@gmail.com

(1) https://orcid.org/0000-0001-9740-8069

\section{Geciane Porto}

Av. Bandeirantes, nº 3900, Monte Alegre, 14040-905, Ribeirão Preto, SP, Brasil.

E-mail: geciane@usp.br

(1) https://orcid.org/0000-0001-6104-3627

* Autora Correspondente

\section{Método de Revisão por Pares}

Este conteúdo foi avaliado utilizando o processo de revisão por pares duplo-cego (double-blind peer-review). A divulgação das informações dos pareceristas constantes na primeira página é feita somente após a conclusão do processo avaliativo, e com o consentimento voluntário dos respectivos pareceristas.
Zahra, S. A., \& George, G. (2002). Absorptive capacity: A review, reconceptualization, and extension. Academy of Management Review, 27(2), 185-203. http://dx.doi.org/10.2307/4134351

Zamberlan, L., Rasia, P. C., Souza, J. D. S. de, Grison, A. J., Gagliardi, A. de O., Teixeira, E. B., Drews, G. A., Vieira, E. P., Brizolla, M. M. B., \& Allebrandt, S. L. (2014). Pesquisa em ciências sociais aplicadas. Ijuí, RS, Brasil: Unijuí.

Zhang, S., Li, N., \& Li, J. (2017). Redefining relational rent. Technological Forecasting and Social Change, 117, 315-326. https://doi.org/10.1016/j. techfore.2016.10.072

\section{Contribuições dos Autores}

$1^{\text {a }}$ autora: Pesquisadora protagonista do estudo, revisita a literatura, coleta e análise de dados. Redação principal do artigo.

$2^{\mathbf{a}}$ autora: Orientadora do estudo, atuou como apoio na construção da revisão de literatura, caminho metodológico, supervisão e validação. Primeira revisora do artigo, responsável pela submissão do artigo e pela correspondência com a revista científica.

$3^{\mathbf{a}}$ autora: Revisão final do artigo, incluindo novos referenciais e trazendo olhares complementares para a discussão dos resultados.

$4^{\mathrm{a}}$ autora: Revisão final do artigo, incluindo novos referenciais e trazendo olhares complementares para a discussão dos resultados.

\section{Financiamento}

Os autores informaram que não houve apoio financeiro para a pesquisa neste artigo.

\section{Conflito de Interesses}

Os autores informaram que não há conflito de interesses.

\section{Direitos Autorais}

A RAC detém os direitos autorais deste conteúdo.

\section{Verificação de Plágio}

A RAC mantém a prática de submeter todos os documentos aprovados para publicação à verificação de plágio, mediante o emprego de ferramentas específicas, e.g.: iThenticate. 